\title{
Socio-Spatial Typology In Karanrang Island
}

\author{
Rahmi Amin Ishak ${ }^{1, *}$, Slamet Trisutomo ${ }^{2}$, Ria Wikantari ${ }^{1}$, and Afifah Harisah $^{1}$ \\ ${ }^{1}$ Architecture Department, Hasanuddin University, Indonesia \\ ${ }^{2}$ Regional and Urban Planning Department, Hasanuddin University, Indonesia
}

\begin{abstract}
The phenomenon of community life on the small island is influenced by the stimulating factor of harmonious social interaction system through cooperation, kinship, economic activity, children playing, transportation system, religion and other social activities. The social dynamics of small island communities appear in the layout and environment in which they live, how they manage and utilize space, both indoors and outdoors. The purpose of this paper is to describe the socio-spatial typology of settlements on Karanrang Island, including a description of the spatial pattern of communalenvironments. Research approaches through spatial similarities and differences in the classification of behavioral setting, including physical, non-physical, socio-spatial arrangements. Karanrang Island as a research focus which has an area of $7.8 \mathrm{Ha}$ is one of small islands inhabited in cluster PangkajeneIslands (Pangkep) South Sulawesi, with characteristic of dense settlement, and diversity of tribe, also inhabited by 434 families. The method of this research is observation, data collection through field survey with descriptive analysis based on empirical data on meso / environment which is divided into:1) inter building space; 2) Space in the building; 3) Open space, and; 4) Environmental facilities. The results showed that classification of socio-spatial typology of communal environment is divided into four types of socio-spatial models based on the configuration of social interaction activities, namely:1) Type of Linear Centripetal, at the inter buildings space; 2) Type of Centripetal Cluster, space on the building; 3) Type of Centrifugal Cluster, at green open space/field; 4) Type of cluster Centripetal, at environmental facilities. The socio-spatial type based on actor's activities, occupancy, and territory, can be distinguished on: 1) Type of children's activity; 2) Type of mother'sactivity; 3) Type of father's activity, and 4) Type of combination activity.
\end{abstract}

Keywords: small island settlement, socio-spatial typology, social settings, spatial settings

\section{Background}

The settlement environment in small islands is influenced by social aspects of society, adaptation to island conditions, and settlement growth. Based on the theory of cultural value orientation by Kluchkohn (1961), the essence of the meaning of community life on the island can affect the spatial order of the settlement and social environment of society, thus binding the community to live. Community settlement and social interaction are also influenced by a series of adaptations to the physical constraints of the island environment, spatial, social, and physical aspects of the environment that affect each other in the formation of the settlement environment.

The growth of settlements on small islands is characterized by the community's attachment to the island, partly due to strong family ties, rural social interactions, hereditary land ownership, and the aspect of a value orientation that is entirely dependent on marine resources. It distinguishes the socio-spatial characteristics of small islands which tend to be solid and homogeneous, with other lands tend to be structured and segregated. In addition, remoteness and isolation factors make the island community more survive and independent in the fulfillment of daily needs. The occurrence of social interaction is characterized by the existence of space encounters both fixed, semi, and temporary, so that social spaces play an important role on the sustainability of social order. The architectural forms of the island environment also affect the activity and behavior of society and vice versa, so that both are in a dynamic cycle, and produce different socio-spatial phenomena at all times.

In order to support the sustainability of the social order and to increase the carrying capacity of the environment of the settlement and conservation of small islands in Pangkep regency, socio-spatial research is needed that focuses on social interaction, in particular the behavior setting on Karanrang Island. The analysis of the socio-spatial typology of small island environments is based on the social behavior setting of the community and the spatial physical condition of the island, within the meso sphere of the settlement environment (inter-building space, space in buildings, open spaces, and environmental facilities).

\section{Literature Review}

\section{Social Space}

Hall (1984) in the 'The Hidden Dimension', states that social space is an abstract space that is not real physical boundaries. Along with this, Lefebvre in 'Production of Space' (1991)

Corresponding author: rahmiamin@unhas.ac.id 
argued that space is a social product, resulting from social constructs based on values and meanings that are produced socially as well, so that space influences the perception of the spatial humans that produce it. If it is assumed that space is a product of the inhabiting process of space, then the result of the process lies in each part of space and becomes the contents of space. The content of space is everything that exists in the space either produced naturally or by society. All that is meant, are living creatures that live in them, objects, work products including signs and symbols located in space. Space is created from the way of living that is influenced by physical aspects (natural conditions), cultural aspects and social relations. Lefebvre (2008) explains that space is created by the way we live in social life (lived space), which in the reality of life intersects with the physical material aspects of the perceived space and the non-material (mental) aspects of space conceived in our minds (conceived space). Therefore, an emerging space is the product of adaptation to the environment and socio-culture.

In a study of environmental and behavioral architecture, Rapoport (1977) classifies the boundaries of public and private space in three main typologies:

1. Type of occupancy: 1) personal occupancy (limited to the scope of the family); 2) community occupancy (limited to one group member or one particular social group); 3) society occupancy (free for the whole community); 4) free occupancy (no restrictions).

2. Space type: 1) urban public (open to all); 2) urban semipublic space (limited users); 3) public group (free for some groups of city dwellers); 4) group private (limited to one family only); 5) family private (limited to one family); 6) individual private (only for individuals).

3. Type of territory: 1) public territory (free for everyone, but must comply with the norms set in the area); 2) interactional territory (an area to communicate between certain social groups); 3) home territory (controlled by one family); 4) body territory (personal space that is individual).

There are two early spatial metaphors used to describe social space, the "ecological zone" model by Baacke and the "island model" by Zeiher. In the ecological zone model Baacke (1999), explains that the social development of children takes place within the local social space. This model illustrates the social attachment of children in concentric circles gradually.

1. The "ecological center" describes the family and home environment, the place where children find firsthand the main personal reference, and where it spends most of its time.

2. "Nearer ecological environment" describes a closer environment that allows children to find first-line relationships outside the family in the neighborhood, in the local area or in the village.

3. "Ecological sectors" describe public places such as schools, playgrounds, shops or swimming pools. They require certain role behaviors and therefore demand new skills from the child.

4. "Ecological periphery" is the field of contact outside of the usual routines such as vacations, trips and contacts to other spaces that are outside of everyday experience.

Further studies by Zeiher (2005) found that ecological zones in concentric layout arrangements are no longer adjacent, but are located in separate zones fed as islands connected. These islands are in a larger space that is only crossed but not all are experienced. Children realize that the island where they live as a center and journey on their way to school, friends and family through other social spaces without feeling connected.

\section{Types of Social Groups}

According to Soekanto (2014) social groups can be divided into two types, namely regular and irregular social groups. Regular types are: 1) In-group and out-group; 2) Primary and secondary groups; 3) Paguyuban and patembayan; 4) formal group and informal group; 5) Membership group and reference group; 6) Occupational and volunteer groups.

Types of irregular social groups, namely:

1. Crowds are individuals who come together by chance at a place at the same time, consisting of casual crowd and lawless crowd

2. The public is a group that is not a unity. Interaction occurs indirectly through communication tools, and tends to be more dominated by individual interests.

3. Communities are people who reside in a region (geographical) with certain territorial boundaries, the dominant interaction between members within their territory.

Criteria for the classification of society are:

- Population;

- The area, resources, and population density of the inland areas;

- Special functions of the local community towards the whole community;

- The local community organization concerned.

\section{Research Methods}

The research using Deinet (2002) approach, to analyze the social space based on the context of qualitative research, are: narrative interviews with "key person" who have a special impression on social space and can share their experiences. In addition, structured interviews were conducted using questionnaires with open questions, to gain a deeper understanding of community activities. Interviews on institutions, with using structured questionnaires, community and institutional staff were asked to provide their assessments of local community and social infrastructure such as schools, day centers, social services, health institutions, and so on.

Identification of socio-spatial typology using spatial ground analysis techniques, overlay mapping and formal descriptive analysis using sketch / drawing techniques. The types of data required include primary and secondary data. Physical aspects of the settlement environment include the unit of analysis: spatial function (fixed, semi, temporary), identity, sign, spatial boundary, center and spatial orientation, frequency of population of social space that often arise. Social aspects of society, including unit analysis: behavioral arrangements (activities, behaviors, roles by age and sex), time and activity frequency. Samples of society as social actors, community leaders, village officials as respondents. Primary data sources: island communities as respondents, community leaders and village heads as informants, and the 
physical situation of the island, housing / buildings and settlements on Karanrang Island. Secondary data are data collected from other sources, such as location maps and statistical data, population demographics. Secondary data sources: village office, statistical data centers, relevant regulations and policies of local agencies, referral literature, and internet search.

Karanrang Island as the focus of the study is part of a group of islands of Pangkep regency, South Sulawesi, Indonesia, spread over the sea area of $11,464.44 \mathrm{~km}^{2}$, there are 114 islands, and 94 uninhabited islands. In the meso / environment scope is divided into: 1) inter-building space; 2) space on the building; 3) open space, and; 4) environmental facilities.

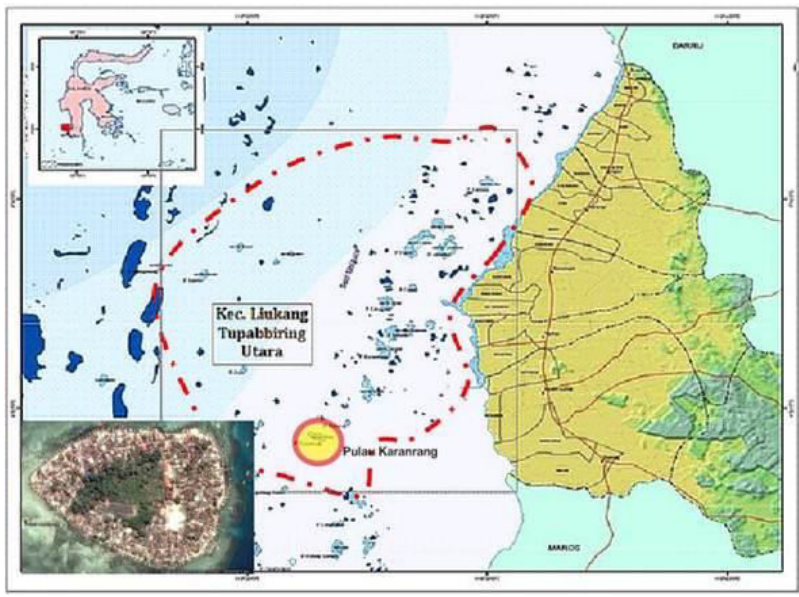

Fig. 1. Locate of Karanrang Island on Pangkep Regency.

\section{Results And Discussion}

\section{Spatial Pattern}

Karanrang Island as an inhabited island, has an elongated settlement pattern and surrounds along the coast of the island, with a generally irregular settlement arrangement. In the central part of the island there are grave area, and green open spaces as groundwater binders, fields, and environmental facilities (Fig. 2). Karanrang Island has high growth settlements and tends to expand to open spaces in the middle of the island and graveyard. The problem of environmental density and land constraints on Karanrang Island is due to the high population growth and high enough housing each year.

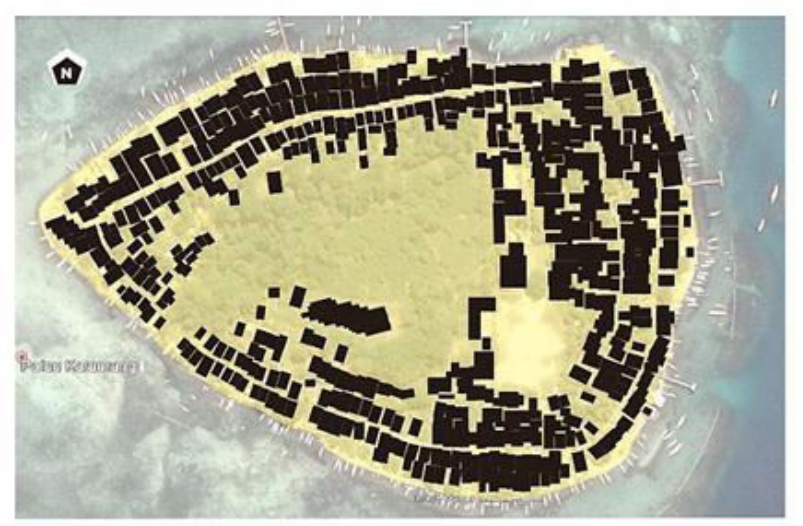

Fig. 2. Figure Ground of Karanrang Island.

Population growth tends to be in line with the growth of houses, in the last year there are 3 - 5 new house built by the population. The current trend of people prefer to build a stone house compared to the stage house. Stone houses are generally built with a fence between the neighboring house, with a more orderly circulation of the road.

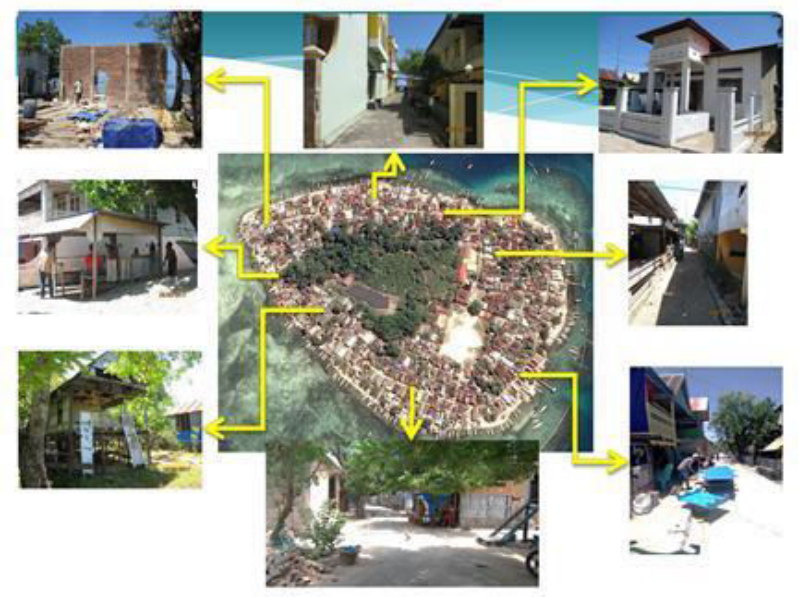

Fig. 3. Spatial Existing Condition of Karanrang Island.

\section{Spatial Function}

Karanrang Island have facilities such as elementary, junior and senior high schools, village health centers (PUSKESDES), mosque and mushallah, and a field/open space located in the center of the island, which is generally close to the settlement $(50-100 \mathrm{~m})$. The location of the mosque/mushallah from the resident's house is generally; $46 \%$ near (50 - $100 \mathrm{~m})$; 39\% far enough (200 - $300 \mathrm{~m})$. The location of daily shopping is generally; $69 \%$ very far (over $500 \mathrm{~m}$ ), the location of education is generally; $77 \%$ near (50 - $100 \mathrm{~m}$ ), the location of the gathering with the neighbors are generally; near $92 \%$ (50 - $100 \mathrm{~m}$ ). 


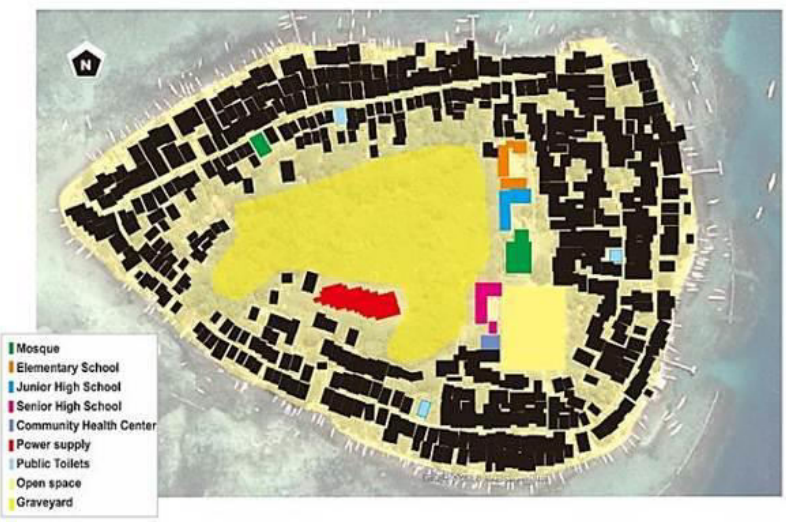

Fig. 4. Spatial Function of Karanrang Island.

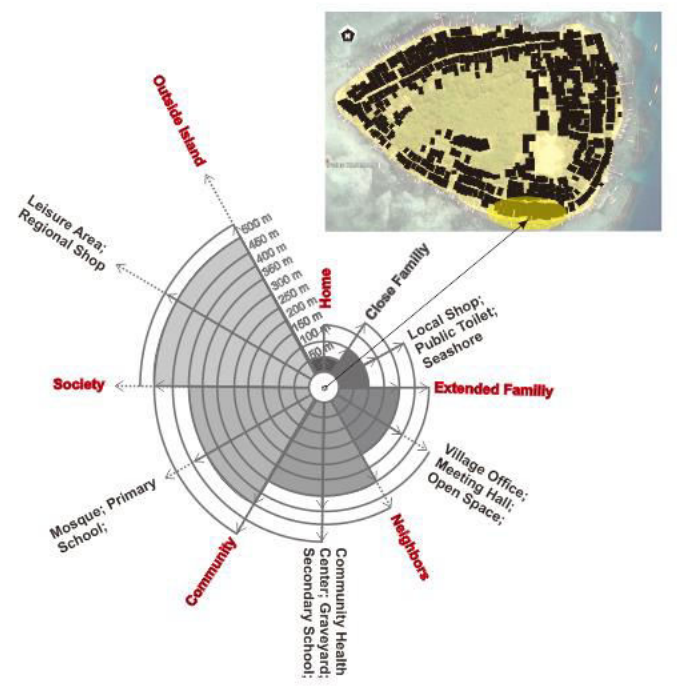

Fig. 5. Distance of facility to residential-edge of the island.

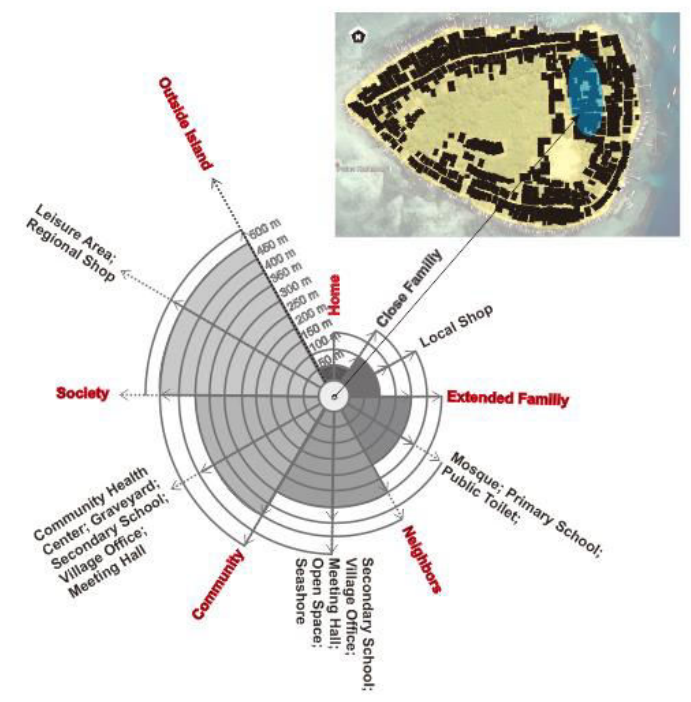

Fig. 6. Distance of facilities to residential-middle of the island.

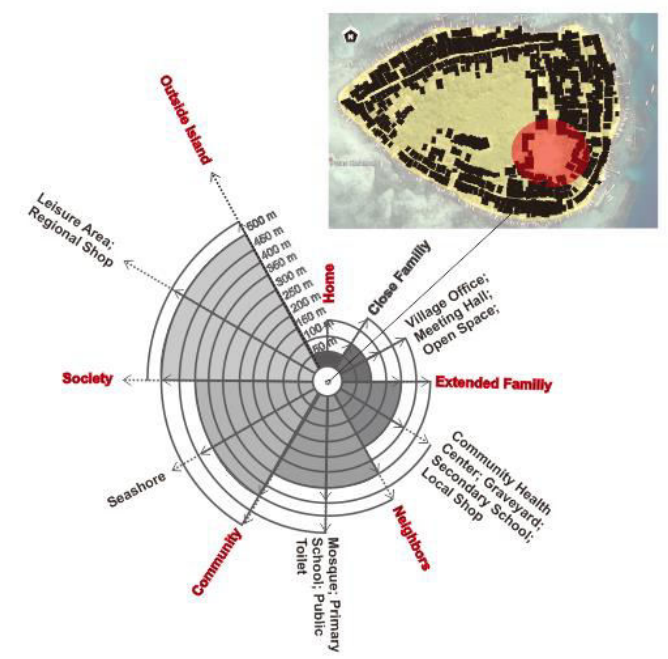

Fig. 7. Distance of facilities to residential-center of the island.

\section{Behavior Setting}

Karanrang Island is dominated by $77 \%$ indigenous people (46\% Bugis-Makassar mixed tribe) and $23 \%$ of migrants. In everyday life, the sea provides a great influence on the population (85\%), as well as a source of livelihood and transportation. The highest education population is generally at the primary level (69\%), and junior high (23\%), the livelihood of head of household is generally fisherman with average income every month generally 1 million - 1.5 million rupiah.

Community social relations in the form of gathering with family or neighbors generally tend around the house (77\%), either in the yard, or in front of the road home. Other activities related to social relations are marriage receptions (46\%), aqiqah (46\%), religious events $(8 \%), 78 \%$ of the community doing activities in front of the house or in the neighborhood, $23 \%$ in open spaces near the house. or field in the middle of the island. Most of the population participates in any social activity $(69 \%)$.

Social interactions such as communication with dominant neighbors take place around the dwelling (77\%). The relationship between communicating activities, reception, visits, or recreational activities with neighbors / families and gathering places, indicates that social interaction activities require space to gather with neighbors / family. Similarly, the relationship between communicating activities with neighbors and house layout, the tendency of communication intensity often occurs in settlements with irregular building layouts (31\%). While the activities of receiving neighbors / guests tend to take place around the house $(77 \%)$.

Based on the settlement layout, visiting activities tend to occur frequently in irregular home layouts. In addition, visiting activities are also linked to the distance between homes. A total of $77 \%$ of houses with a building distance of 1-2 meters tended to have higher interaction with neighbors, compared to houses with a building distance of 3-4 meters. It also appears on the pattern of circulation path and visiting activity, the tendency of such activity occurs in irregular circulation patterns $(46 \%)$. 
Visiting neighbors tends to take place in circulation paths and irregular settlement layouts (54\%). Related distance between buildings, visiting activities tend to take place in buildings with a distance of 1-2 meters (69\%). This activity is also associated with a gathering place around the house (77\%). Based on the circulation pattern, people tend to visit neighbors in the settlement with irregular circulation patterns (46\%).

\section{Typology of Socio-Spatial}

To achieve full socio-spatial dynamics, social space analysis needs to focus on interactive and relational interactions between individuals and social structures. The concept of social space can be used as a metaphor for this perspective and helps analyze the process of social networking and its interrelationships.

The following table 1 shows some behavior setting that happened on: 1) inter buildings space; 2) space on the building; 3) open space, and; 4) environmental infrastructure. Configuration and character of the activity tend to be affected by the behavioral setting of the activity, activity type, and user activity. Communal play activities by children in open spaces tend to be dynamicspreading, whereas individual play activities under trees, on boats, or in the hallway tend to be static-centered. Social interactions that occur in inter-building space tend to occur incidentally and temporally, where the distance between buildings and circulation patterns also affect the frequency and intensity of interactions that occur.

Table 1. Configuration of Character and Activity on Karanrang Island.

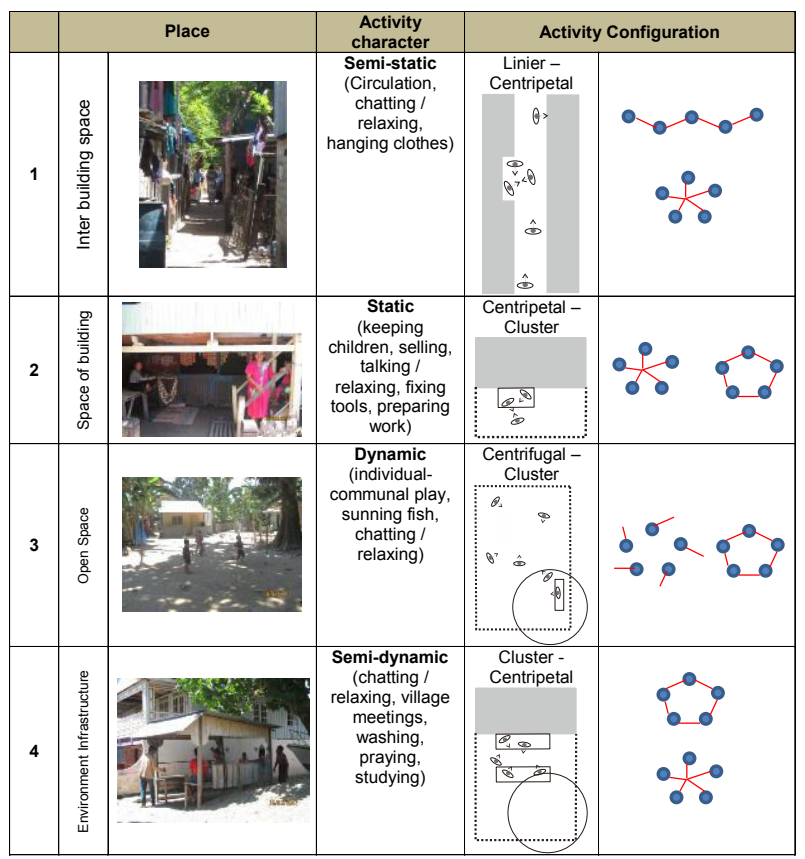

Based on the type of actor's activity, occupancy and spatial territory, the socio-spatial type on Karanrang Island can be distinguished on: 1) Type of children's activity; 2)
Type of mother's activity; 3) Type of father's activity, and 4) Type of combination activity.

Children's social space moves from home to major environmental facilities (schools, mosques, green open spaces), then to beachside playgrounds, and on holiday out of the island. Children's daily activities on the island tend to spread in the middle and edge of the island, while the center of the island or village is a field and graveyard, which tend to be rarely visited by children, especially during the day. Children prefer to play in a shady and sheltered environment (Fig. 8).

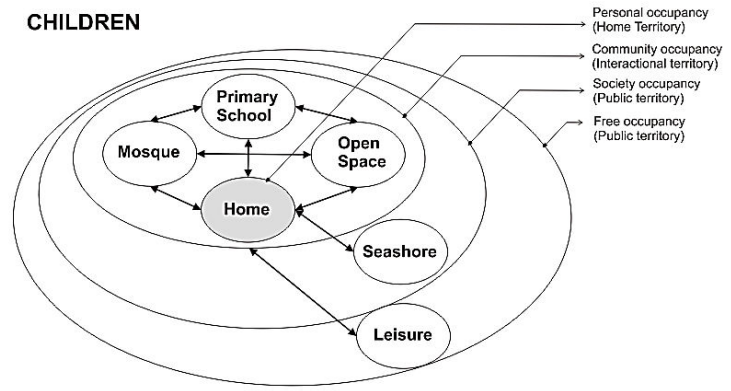

Fig. 8. Type of socio-spatial activity of children on Karanrang Island.

Compared with the daily activities of children, the daily activities of mothers tend to be more varied. The main social interaction space of mothers moves from house to family home / neighbor - public toilets - and stalls. While the weekly secondary activity is a recitation activity in the mosque - checking health at the health center - a celebration event - chatting / relaxing on the beach. Monthly shopping activities tend to be conducted in regional markets outside the island (Fig. 9).

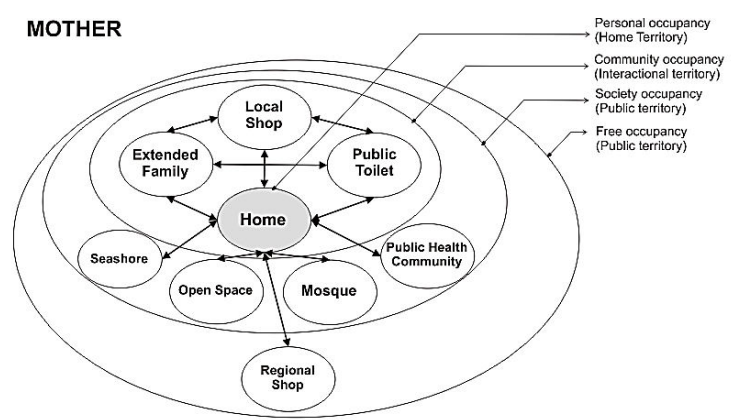

Fig. 9. Type of socio-spatial activity of mothers on Karanrang Island.

The activities of fathers, who work as fishermen tend to spend more time on the seas and beaches. Generally the father's social space moves from home - family / neighbor beach - green open space. Weekly / monthly meeting activities tend to be in the Village Office - Mosque / Mushallah - Village Health Center - Village Hall. The furthest activities outside the island are often conducted outside the island to go to the sea, trade or shop for basic necessities (Fig. 10). 


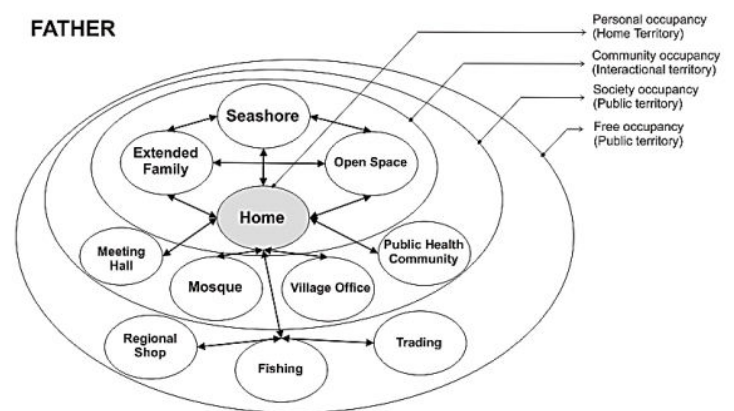

Fig. 10. Type of socio-spatial activity of fathers on Karanrang Island.

The combination type of children's - mother's - father's activities, tend to spend more time on 3 zones. Generally the combination's type of social space moves from home family / neighbor - green open space. Weekly / monthly meeting activities tend to be in Mosque / Mushallah - Public Health Community - Seashore. The furthest activities outside island, often conducted to Regional Shop for primary and secondary necessities, also to have some leisure (Fig. 11).

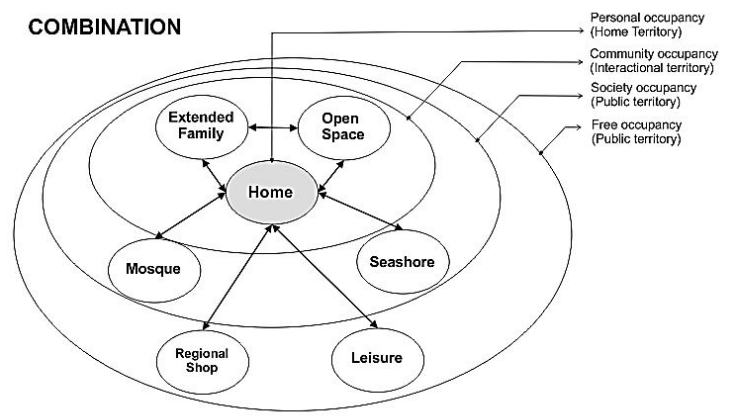

Fig. 11. Type of socio-spatial activity combination on Karanrang Island.

Social space is not merely a "container" but a relational arrangement of people and material goods in certain places that are always dynamic and fluid. Through the process of "distance" one can acquire material places, establish new relationships and create new social spaces of their own (Deinet, 2009). In this sense, space is always socially determined. In addition, this understanding allows multiple social spaces in one geographic place to be identified. Social space can be changed and also disappears as their producers leave the place. Following this idea, social space can be regarded as a small and temporary community at the local and regional levels.

To achieve full socio-spatial dynamics, social space analysis needs to focus on interactive and relational interactions between individuals and social structures. The concept of social space can be used as a metaphor for this perspective and helps analyze the process of social networking and its interrelationships.

\section{Conclusion}

The socio-spatial typology on Karanrang Island is distinguished based on the characteristics of the social interaction on behavior setting, and divided by type of social space (inter buildings space, space in buildings, open space, and environmental facilities).

In the meso / settlement environment, there are four types of socio-spatial models based on the configuration of social interaction activities, namely: 1) Type of Linear - Centripetal, at the inter buildings space; 2) Type of Centripetal - Cluster, at space on the building; 3) Type of Centrifugal - Cluster, at green open space / field; 4) Type of Cluster - Centripetal , at environmental facilities.

The socio-spatial type based on actor's activities, occupancy, and territory, can be distinguished on: 1) Type of children's activity; 2) Type of mother's activity; 3) Type of father's activity, and 4) Type of combination activity.

\section{References}

Baacke, Dieter (1999): "Die neue Medien-Generation im New Age of visual thinking: Kinder- lind Jugendkllitur in der Medienkultur". Leske + Budrich, Opladen.

Deinet, Ulrich (2009), Methodenbuch Sozialraum, VS Verlag für Sozialwissenschaften | GWV Fachverlage GmbH, Wiesbaden.

Hall, Edward T. (1984) The Hidden Dimension, Anchor Books Editions, USA.

Hengst, Heinz; Zeiher, Helga (2005) Kindheit Soziologisch, VS Verlag für Sozialwissenschaften GWV Fachverlage GmbH, Wiesbaden.

Koentjaraningrat (1995), Pengantar Ilmu Antropologi, Aksara Baru, Jakarta.

Laurens, J. Marcella (2004), Arsitektur Perilaku Manusia, PT. Gramedia Widiasarana Indonesia, Surabaya.

Lefebvre, Henry (1991), The Production of Space, Oxford, UK \& Cambridge, USA: Blackwell

Madanipour, A (1996), Design of Urban Space, in Inquiri into a Socio-Spatial Process, John Wiley \& Sons, New York.

Rapoport, A. (1969). House Form \& Culture. Englewood Cliffs, N.J: Prentice-Hall

Rapoport, Amos (2005), Culture, Architecture, and Design, Locke Science Publishing Company, Inc, Chicago.

Ritzer, George. Editor (2005) Encyclopedia of Social Theory, Volume 1, California: Sage Publications, Inc.

Ritzer, George. Editor (2005) Encyclopedia of Social Theory, Volume 2, California: Sage Publications, Inc.

Ritzer, George \& Smart, Barry (2003) Handbook of Social Theory, California: Sage Publications, Inc. 
Spatscheck \& Ostermann (2009) Social Space Analysis and the Socio-Spatial Paradigm in Social Work, Working-paper serien 2009:1, ISSN 1650-8971. 